Article

\title{
Evaluation of the Impact of Weather-Related Limitations on the Installation of Offshore Wind Turbine Towers
}

\author{
Stephan Oelker ${ }^{1,2, * \mathbb{D}}$, Aljoscha Sander ${ }^{3,4} \mathbb{D}^{\mathbb{D}}$, Markus Kreutz $^{1} \mathbb{D}$, Abderrahim Ait-Alla ${ }^{2}$ and Michael Freitag ${ }^{1,2} \mathbb{D}^{\mathbb{D}}$ \\ 1 Planning and Control of Production and Logistics Systems (PSPS), Faculty of Production Engineering, \\ University of Bremen, c/o BIBA, Hochschulring 20, 28359 Bremen, Germany; kre@biba.uni-bremen.de (M.K.); \\ fre@biba.uni-bremen.de (M.F.) \\ 2 BIBA-Bremer Institut für Produktion und Logistik, Hochschulring 20, 28359 Bremen, Germany; \\ ait@biba.uni-bremen.de \\ 3 Institute for Integrated Product Development (BIK), Faculty of Production Engineering, University of Bremen, \\ Badgasteiner Straße 1, 28359 Bremen, Germany; alsander@uni-bremen.de or aljoscha.sander@rug.nl \\ 4 Energy and Sustainability Research Institute Groningen, University of Groningen, \\ 9747 Groningen, The Netherlands \\ * Correspondence: soelker@uni-bremen.de; Tel.: +49-421-218-50130
}

check for updates

Citation: Oelker, S.; Sander, A.; Kreutz, M.; Ait-Alla, A.; Freitag, M. Evaluation of the Impact of Weather-Related Limitations on the Installation of Offshore Wind Turbine Towers. Energies 2021, 14, 3778. https://doi.org/10.3390/en14133778

Academic Editor: José A. F. O. Correia

Received: 30 May 2021

Accepted: 15 June 2021

Published: 23 June 2021

Publisher's Note: MDPI stays neutral with regard to jurisdictional claims in published maps and institutional affiliations.

Copyright: (c) 2021 by the authors. Licensee MDPI, Basel, Switzerland. This article is an open access article distributed under the terms and conditions of the Creative Commons Attribution (CC BY) license (https:// creativecommons.org/licenses/by/ $4.0 /)$.

\begin{abstract}
Weather conditions have a significant impact on the installation of offshore wind turbines. The rules for installation set clear limits. These limits are usually based on estimations of various experts and not on real assumptions and measurements on-site. When wind speeds and wave heights are too high, work cannot be carried out, and this leads to delays and additional costs. Therefore, we have carried out a measurement campaign during the installation of rotor blades to investigate to which extent the limits can be adjusted by using a tuned mass damper. The results from the measurement campaign—specifically empirically derived significant wave height limits—are used in a discrete event simulation. This study simulates delays resulting from weather conditions. Based on this, the total installation costs are considered. The results of the measurement campaign show that a safe installation with the use of a damper is possible at wave heights of up to $1.6 \mathrm{~m}$. With the discrete event simulation, it is possible to prove that $17.9 \%$ can be saved for the costs of the installation vessel. In addition, the wind farm could be erected 32 days faster. Thus, it can be stated that the use of a tuned mass damper simplifies the installation from a technical point of view and is economical.
\end{abstract}

Keywords: offshore wind energy; installation planning of offshore wind parks; discrete event simulation; measurements; weather influences

\section{Introduction}

Offshore wind energy is getting more and more in direct competition with fossil energy. Countries, such as Germany, are gradually rolling off their subsidization programs towards subsidy-free offshore wind energy. Hence, offshore wind energy requires innovation, as current processes are cost-intensive. Installation alone can make up $18 \%$ of the total cost in an offshore wind park [1]. Two approaches are feasible with innovations or improvements: Radical disruption by a complete redesign or an entirely new concept and incremental innovation of existing processes or services. To decide which innovation or improvement to pursue, a realistic economic and physical evaluation of the innovation's feasibility is needed. For processes, such as installing offshore wind parks, discrete event simulations allow for risk, and therefore, cost assessment.

Furthermore, potential innovations or improvements can directly be assessed as to their possible impact on cost reduction. Various authors have applied this approach successfully. Barlow et al. investigated the impact of innovative developments on the installation process for an offshore wind farm [2]. In a further study in 2017, Barlow et al. developed a framework to support logistical decisions in installing offshore wind farms [3]. In addition, Beinke et al. in 2017 conducted a simulation study to investigate the 
impact of a resource-sharing approach to installing an offshore wind farm [4], and Byon et al. in 2017 conducted a simulation of the operation and maintenance of a wind farm [5]. However, as these simulations depend on the availability and quality of weather data and the accuracy of process times and descriptions, results may differ from reality. To mitigate these uncertainties, processes can be afflicted with a certain probability of delay. Rerunning scenarios then yield average process times [6]. Furthermore, discrete event simulations do not take the physics involved in specific process steps into account, which can be restricted by environmental limits, such as wave height and wind speed. While these simulations can answer the question "what is the impact of a certain process delay on the overall process duration", discrete event simulations yield no insight into the cause of delay. This becomes more relevant when involved process steps depend on phenomena that are non-linear and transient by nature, such as turbulence or wave and wind impact on marine structures. Physical simulations or in-situ measurement campaigns must then be used to determine the cause.

Figure 1 lays out the concept of the present study. A discrete event simulation setup will be implemented, where the installation process limits, obtained through the results of a measurement campaign, will be applied as boundary conditions.
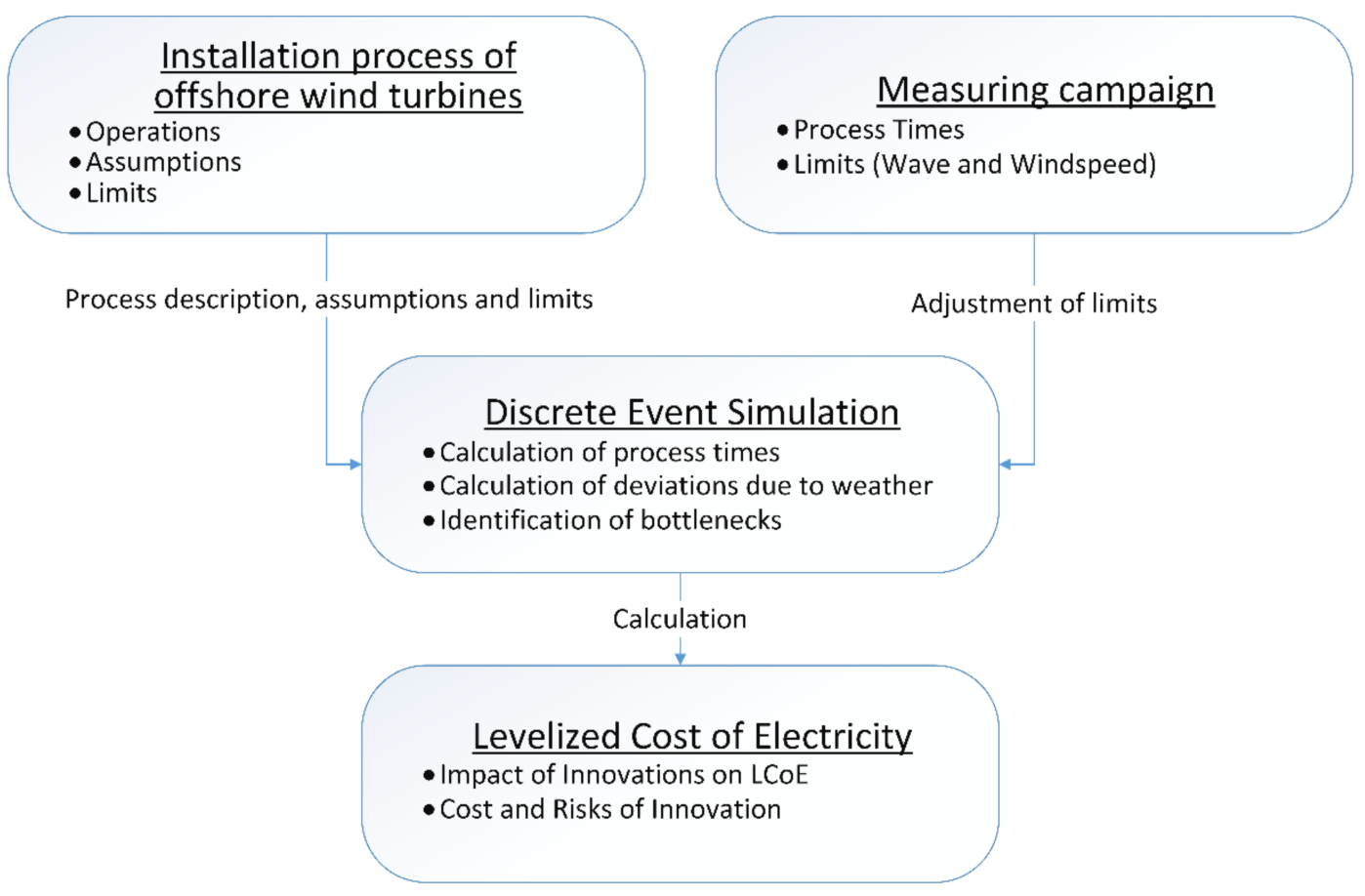

Figure 1. Concept of connecting simulation and measurement campaign.

One of the main objectives for developing innovations in offshore wind energy is to reduce the Levelized Cost of Electricity (LCoE). Thus, the discrete event simulations' results estimate the overall installation costs, and the influence of installation bottlenecks or the effect of process innovation on LcoE is calculated.

The installation process limits were obtained during the installation of the offshore wind park Trianel Windpark Borkum II (TWBII); extensive measurements were carried out to capture both installation times and the physical behavior of turbines and blades undergoing installation. For further reference regarding details of the measurement campaign, please see the publications of Sander et al. $[7,8]$. The measurement data is available at https:/ / zenodo.org/record/4498779 (accessed on 8 June 2021) [9]. Using field data, such as the measurements from the TWBII installation, process times, and-by combining field data with meteorological date-installation limits can be derived to yield realistic boundary conditions for discrete event simulations. The measurement data from the TWBII 
installation are of additional interest to investigate installation performance as 16 out of a total of 32 turbines were installed using a tuned mass damper in the nacelle during single blade installation, which in turn resulted in higher environmental limits for blade installation $[7,8]$. Adding a tuned mass damper to enhance installation performance is a possible process innovation that results in less austere environmental installation limits and can be modeled accordingly in discrete event simulations.

In this study, the combination of a discrete event simulation and a real measurement campaign will be used to identify potential savings in the use of tuned mass dampers for installing rotor blades. In particular, we look at the opportunities for reducing the LCOE that result from the use of a tuned mass damper. Thus, installing TWBII is simulated using discrete event simulations. Initial and boundary conditions for the discrete event simulations are derived from the measurement campaign. Once the baseline scenario TWBII is modeled, environmental limits are varied to assess the impact of the different limits on the overall installation time and costs. These variations in environmental limits include the installation limits observed during installing TWBII with a tuned mass damper present, but also exceed these limits to assess the impact of additional installation process innovations.

\section{State of the Art}

\subsection{Conventional Offshore Wind Park Installation}

Conventional offshore wind park installation starts with the installation of foundations into the seabed. Different types and concepts of foundations have emerged during the history of offshore wind parks. Among them, the monopile foundation type has been the common choice for water depths up to $30 \mathrm{~m}[10,11]$.

In parallel, the transport of required wind turbine components from their respective production ports to a specified base port near the planned offshore wind park location occurs. These components include the tower, the three rotor blades, and the nacelle, which contains the drive train and sits on top of the tower. When the actual installation starts, a jack-up installation vessel loads the components according to their capacity at the base port, moves to the wind park location, installs wind turbines by assembling the wind turbine parts, moves back to the base port, and repeats this process until all wind turbines are installed. To be able to perform the installation, the vessel comes with a heavy-lift crane installed. Furthermore, the vessel includes jack-up "legs" that extend downwards until touching the seabed to lift the vessel above sea level, ensuring the vessel's stability during the installation, making the process independent from wave height restrictions. Due to these specific functions, the charter rates of $€ 70,000-€ 145,000$ per day for these special ships are high $[6,12]$. Besides the described steps, some further steps, such as cable installation and commissioning, are also part of the installation process [13].

One of the main disadvantages of the conventional installation process is assembling the wind turbine components directly at sea. High wind speeds occur, which are beneficial once the wind park is put into operation, but unfavorable, while installing a delicate turbine part as the blade. This causes waiting times for the expensive installation vessel [6].

Nevertheless, the conventional installation concept is still widely used as it has proven itself as a successful and reliable way for offshore wind park installation. Alternative concepts, such as the offshore feeder concept, in which the components are transported to the installation vessel by a transport ship, have similar problems. Or rather, the issues are even more significant here, as the lifting processes are significantly more complex [6]. Weather conditions also affect floating concepts, where the turbines are placed on a platform and can be assembled in the harbor [13]. This is possible because the platform floats on itself and can be towed by a vessel to the installation site. Weather conditions have a significant impact on transport and anchoring. Depending on the concept, this can then be done with an already fully installed system or components, such as the rotor blades are installed in the field. 
For both installation and nominal operations, vibrations play have a huge impact; artificially adding damping to the system to influence these vibrations has, therefore, been widely covered in the literature. A simple and well-proven approach to reducing vibration amplitudes is the deployment of tuned mass dampers. These simple systems feature a damping mass, attached to both spring and damping elements, that can move freely within a certain range inside of the turbine. Due to a phase lag between the motion of the turbine and the damper's mass, additional damping is added to the turbine. To achieve maximum efficiency of a tuned mass damper, the eigenfrequency of the damper must be aligned with the eigenfrequency of the turbine. Many modern wind turbines feature tuned mass dampers, though they are usually designed for nominal operations, not for installation. Recent studies showed a potential for tuned mass dampers to improve both nacelle and blade installation in offshore wind turbines [14-16]. However, these studies rely on numerical models to accurately model the physics of installations. To our knowledge, the tuned mass damper used during the installation of the offshore wind farm Trianel Windpark Borkum II was the first tuned mass damper that was specifically designed and deployed for single blade installation. For details, please refer to [8].

\subsection{Previous Research Regarding Offshore Wind Park Installation}

Available research regarding installing offshore wind parks mainly focused on optimizing conventional installation concerning parameters, such as weather and resource restrictions. Two main streams of works emerged to deal with the planning of the installation of offshore wind parks. The first stream focuses on optimizing the installation planning using mathematical models, whereas the second stream used the simulation approach to model the different installation processes using a discrete event simulation model to evaluate specific assumptions and configurations. Ait Alla et al. and Irawan et al. used mathematical models to generate an installation schedule [17,18]. Thereby, Ait Alla et al. proposed a mathematical model to generate an aggregate medium-term installation plan with the objective of cost reduction [17]. Irawan et al. developed a mathematical model using integer linear programming to determine the optimal installation schedule that minimizes total installation cost or total completion period [18]. They propose a bi-objective optimization model that focuses on finding a trade-off between minimal construction times and costs. As the scheduling problem is nondeterministic polynomial-hard, they apply Compromise Programming using greedy heuristics to reduce computational efforts.

In Rippel et al., a mixed integer formulation for optimizing supply deliveries to the base port is proposed [19]. Furthermore, an example of integrating this formulation into a base port capacity optimization is presented, and a simulation study of the impact of different resupply cycles on the efficiency of installation projects is conducted. The results show that the resupply cycle has a small impact on the efficiency of the project, but an enormous impact on the capacity of the base port.

Considering literature dealing with the simulation approach, Ait Alla et al., Muhabie et al., and Vis and Ursavas apply a simulation-based approach using discrete event simulation models to determine the installation plan and processes sensitive to weather restrictions [11,20,21]. In 2018, Muhabie et al. investigated the most effective approach to installing offshore wind parks using discrete event simulation. In this context, deterministic and probabilistic weather conditions were considered in their model to assess the impact of weather conditions on the installation processes. In 2017, Ait Alla et al. proposed a multi-agent-based simulation model to compare the conventional installation concept with feeder concepts considering different factors like the number of wind turbines and the distance of the wind park from shore. In 2019, Rippel et al. provide an extensive overview of research efforts into simulating the installation of offshore wind parks [22]. More details about the current state of offshore wind turbine installations can be found in Jiang's technical review [13].

All previous studies cited above that have analyzed the installation costs of wind farms are only based on estimated process descriptions, but not on real process measurements like 
this study. To our best knowledge, there is no work that uses real process measurements and investigates the impact of weather-related waiting times in the installation of offshore wind turbines when innovative technologies change weather and process conditions.

\subsection{Field and Simulation Data}

Due to very limited access to offshore wind park installations and the associated cost of accessing installation sites, few in-situ experiments targeting the process of installation have been carried out. In 2018, Maess et al. used an integrated GNSS-IMU approach to track blade motions during crane operations to assess the induction of motions onto the blade by the crane [23]. However, the measurements took place in the harbor at the quay; thus, no significant waves were present.

Other studies utilized Supervisory Control and Data Acquisition data from operational wind turbines. However, these data do not cover the installation phase [24-27] as the turbines are typically not online during installation.

Several numerical studies have been carried out investigating turbine behavior during turbine installation. Most studies concluded that wind-induced motions of the blade and wind and wave-induced motions of the tower limit the installation of blades [28-31].

\section{Material and Methods}

\subsection{Trianel Windpark Borkum II Installation}

The Trianel Windpark Borkum is an offshore wind park in the German Exclusive Economic Zone in the southern North Sea. It was built in two phases with $200 \mathrm{MW}$ each. The turbines of phase 1 have been in operation since 2015. The installation of the second stage, Trianel Windpark Borkum II, began on the 1 August 2019. The base harbor for the project was Eemshaven in the Netherlands. Two different jack-up vessels were used: Jan de Nul's Taillevent and Fred Olsen Wind Carrier's Blue Tern, as shown in Figure 2. The turbines are 32 Senvion 6.2M152 with a rated power of 6.33 MW, a rotor diameter of $152.0 \mathrm{~m}$, and a hub height of $104.5 \mathrm{~m}$ above mean sea level. The park is located northwest of the German island Borkum. Notably, 16 out of 32 turbines were installed with a tuned mass damper specifically designed to be used during single blade installation. The tuned mass damper targeted the first fore-aft and side-side frequency of the turbine during installation, significantly reducing tower top motions, thus simplifying single blade installation. The tuned mass damper was used for turbines 17 to 32 during the winter months of the installation.

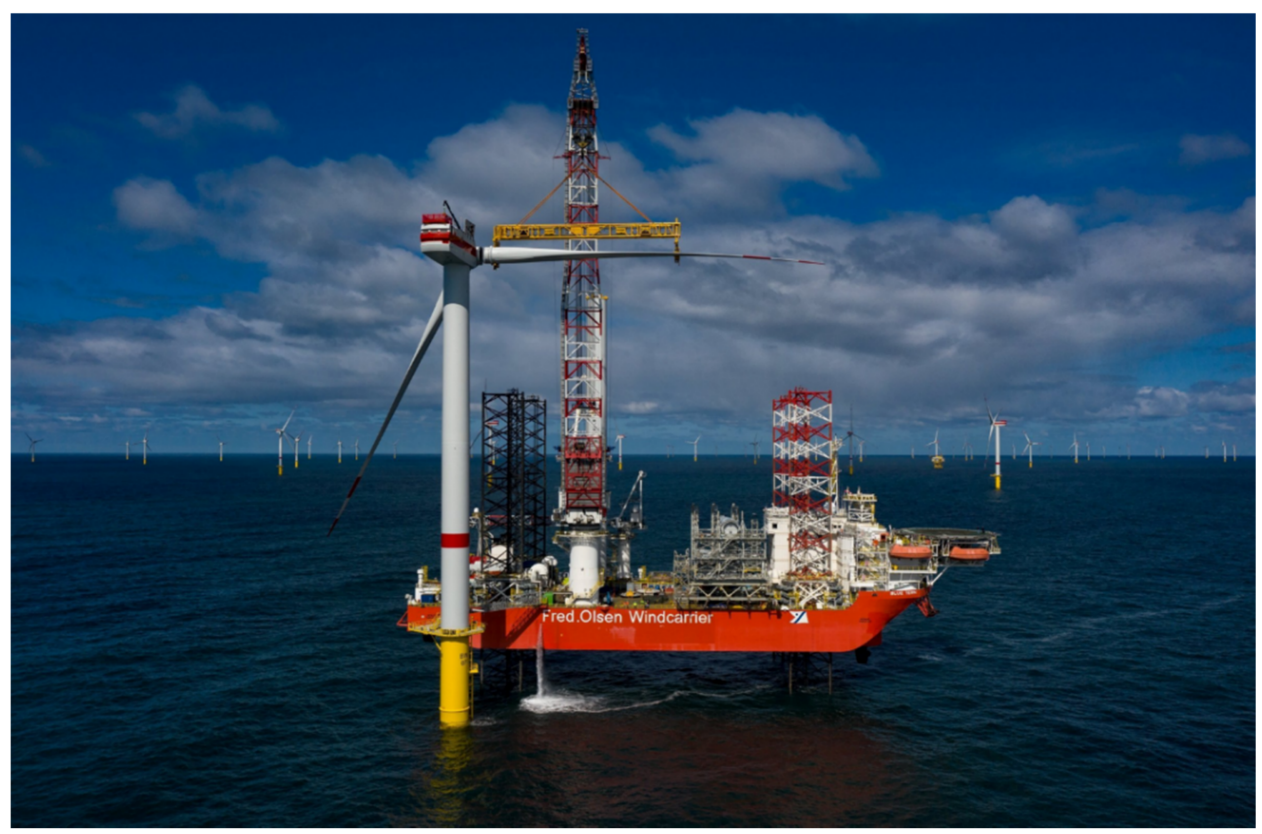

Figure 2. Blade installation taking place at Trianel Windpark Borkum II. 
A set of motion sensor boxes was deployed during the installation campaign to acquire process times and to monitor the structural response of the turbines during installation. Figure 3 illustrates the placement of the motion sensor boxes.
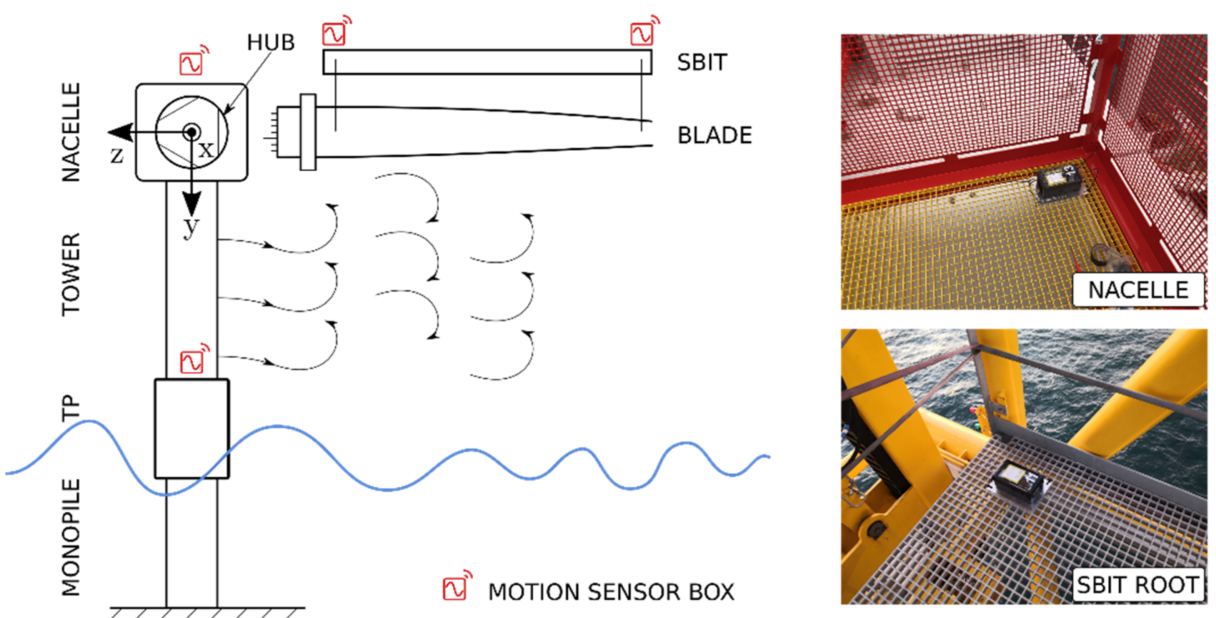

Figure 3. Placement of motion sensor boxes on different components during the installation of Trianel Windpark Borkum II. The blade lifting yoke is abbreviated as SBIT (Single Blade Installation Tool). The two images on the right show the sensor boxes placed on the helicopter hoisting platform atop the nacelle (top image), the SBIT, blade root side (bottom image). Modified after Sander et al. [7].

The motion sensor boxes featured Global Navigation Satellite Systems (GNSS) receivers and linear acceleration, angular velocity, and magnetic field sensors, as shown in Figure 4. Sensor boxes were installed on the transition piece, on the nacelle, and on the blade lifting yoke- the latter featured two sensor boxes to enable blade orientation during installation. With the deployment of the tuned mass damper, an additional sensor box was placed on the tuned mass damper, yielding both activation times, as well as relative motions between the turbine and the damping mass.

The measurement campaign showed that the average installation time during the installation of the blades was $4 \mathrm{~h}$. After the tuned mass damper was deployed for turbines 17-32, installation time was reduced to $2.5 \mathrm{~h}$. In addition, it was shown that the wave height, in particular, influenced the successful installation of the rotor blades, which was not initially considered as an essential factor in the planning phase of the installation. In fact, the wave height induces strong tower top motions, while the wind speed had only a minor influence on the blade dangling from the crane. The use of the damper has also led to significant advantages here. Figure 5 shows the distribution of successful installations of the rotor blades depending on the wave height. Without the damper, most blades were installed at significant wave heights below $1.25 \mathrm{~m}$. It should be mentioned that the installation attempts were carried out with and without dampers at different wave heights over the shown spectrum. Unfortunately, the number of failed installation attempts has not been recorded. With the use of the tuned mass damper, the blades were installed at a much higher significant wave height (up to $2 \mathrm{~m}$ ) [32], where most installations were carried out at a wave height of $1.25 \mathrm{~m}$. 

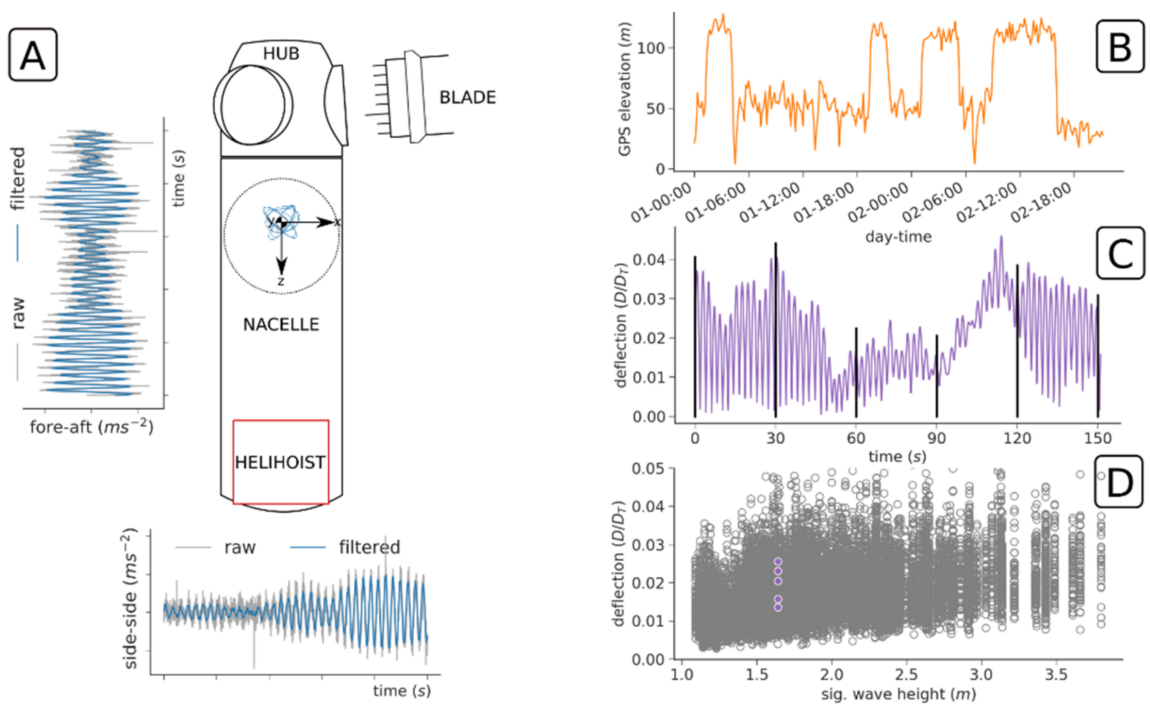

Figure 4. Data acquired by the motion sensor boxes installed on top of the nacelle. (A) the raw accelerations were filtered and numerically integrated twice, resulting in the trajectory of the nacelle in the seaplane. GNSS altitude tracks (B) recorded simultaneously at the blade lifting yoke reveal installation times. Calculating the absolute value of the locus vector of the nacelle results in the deflection, a measure for the amount of distance the nacelle has been moved from its resting position (C). Combining deflection and sea state data reveals the correlation between significant wave height and structural response in the form of deflection (D). Further details on the measurement campaign are provided by Sander et al. [7,8]. The measurement data is available at https://zenodo.org/record/ 4498779 (accessed on 8 June 2021) [9].

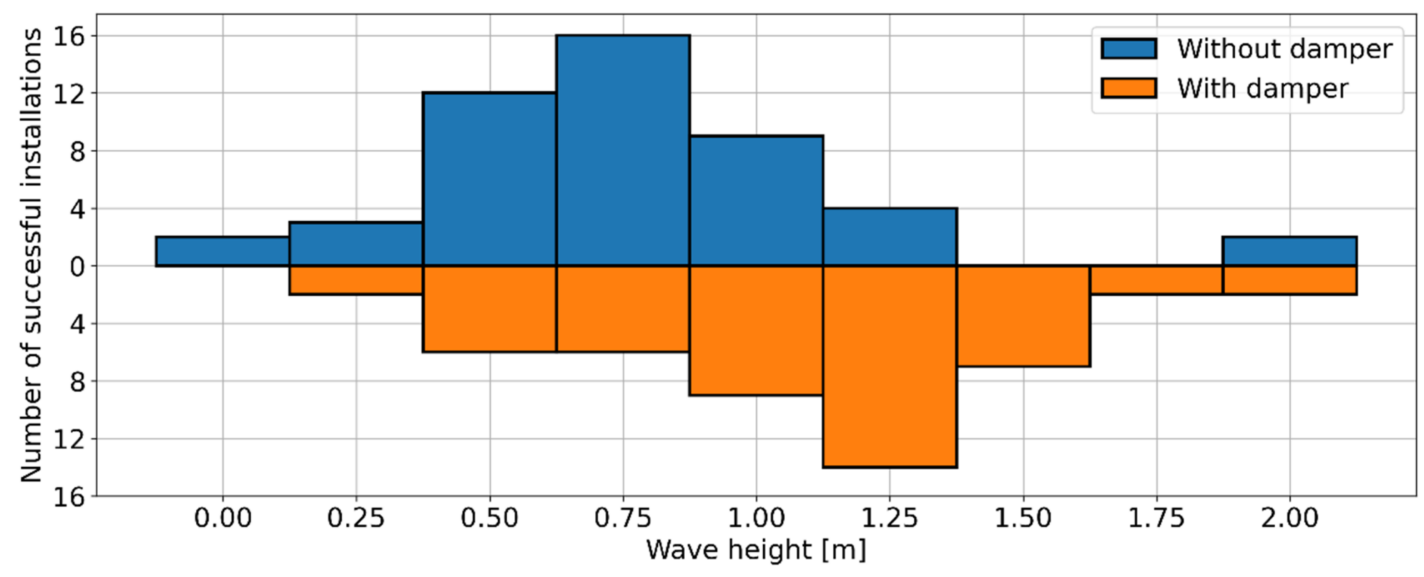

Figure 5. Distribution of wave height during successful blade installations [29].

\subsection{Simulation Scenario for the Discrete Event Simulation}

The simulation study represents the installation of the wind park TWBII. Within this study, 32 wind turbines are installed in the southern North Sea, approximately $50 \mathrm{~km}$ away from shore. The installation scenario is a conventional installation using fixed foundations (monopiles) that starts on the 1st of August, utilizing a jack-up vessel that can install three turbines per cycle.

As most of the processes during installation are subject to weather condition restrictions, around ten years of historical weather data (1991 to 2000) were used to represent a realistic range of weather conditions that include years, which were especially suitable or unfavorable for the installation [33]. 
Figure 6 shows a simplified overview of the processes for the conventional installation of an offshore wind turbine. Each of the illustrated processes consists of several sub-steps that are not shown for the sake of a clear overview. Every step has an expected operation duration and restriction. In reality, the execution duration of a process varies, depending on various circumstances. Thus, a triangular distribution was applied to the process duration to account for variations in execution duration. The triangular distribution was chosen such that the process is completed in $120 \%$ of the time of the expected duration for the worst possible case, and in $90 \%$ of the time in for the best case.

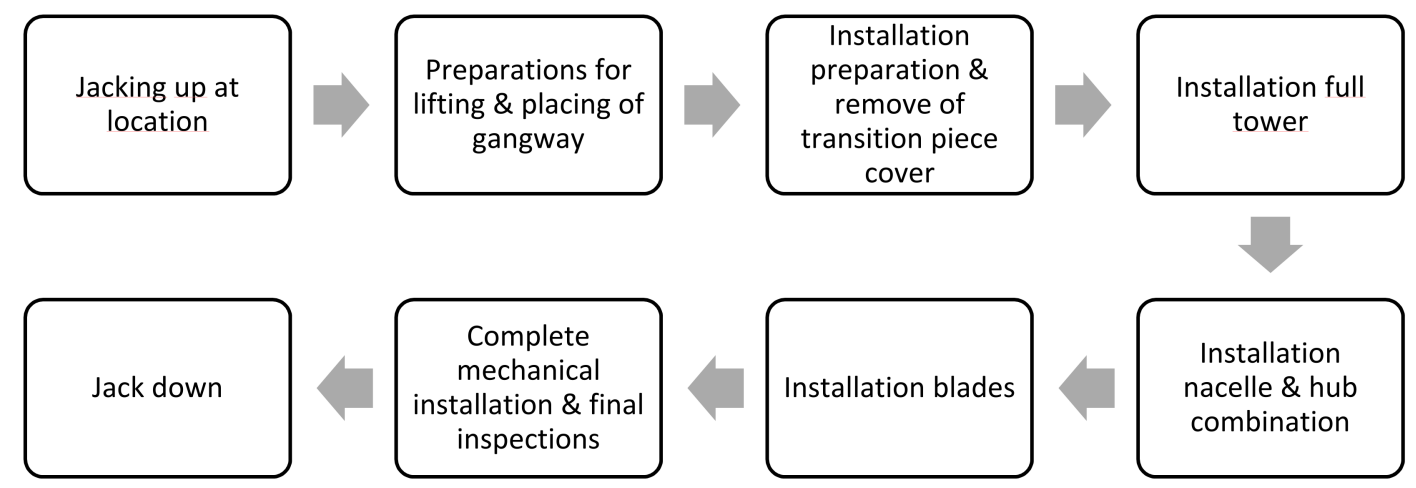

Figure 6. The installation process of an offshore wind turbine.

The benefits of improving the single blade installation are investigated by performing a parameter variation for the wave height limit for this process step. The limit for the execution of the installation process is set at 1.0, 1.3, 1.6, and $1.9 \mathrm{~m}$ significant wave height in the simulation. The limits were chosen based on the measurement campaign carried out, as the most significant changes were expected. The wind speed limit is fixed to $12 \mathrm{~m} / \mathrm{s}$. In addition, a learning curve was considered when installing the rotor blades.

Moreover, realistic cost rates following Oelker et al. have been included [6]. One hundred simulations were run in total for every wave height limit configuration. The main parameters for the rotor blade installation process are summarized in Table 1.

Table 1. Overview of limits used for blade installation in the simulation.

\begin{tabular}{cc}
\hline Parameter & Value \\
\hline Limit wave height & $1.0,1.3,1.6$ and $1.9 \mathrm{~m}$ \\
Limit wind speed & $12.0 \mathrm{~m}$ per second \\
Mean installation time & $4.0 \mathrm{~h}$ \\
\hline
\end{tabular}

In particular, the costs and waiting times for the installation vessel are considered within the simulation framework. For this purpose, the results are compared with each other in the different configurations.

\section{Results and Discussion \\ Discrete Event Simulation}

Figure 7 shows the development of the costs for the installation vessel in the modeled scenarios. The costs for the charter of the vessel, the crew, and fuel costs were considered. Increasing the allowable limit for significant wave height from 1.0 to $1.3 \mathrm{~m}$, the median for potential savings for the installation vessel is $13.1 \%$. If the limit raises to $1.6 \mathrm{~m}, 17.9 \%$ (median) of the costs can be saved. Beyond that, the potential savings are less significant. With a significant wave height of $1.9 \mathrm{~m}$, the median is $22.1 \%$ for the savings. 


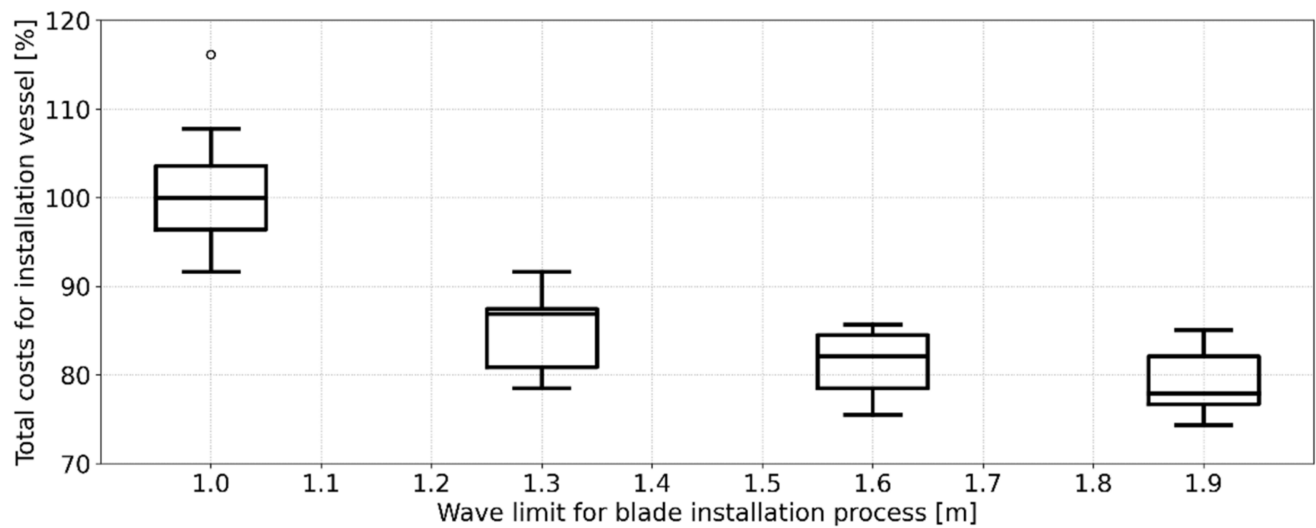

Figure 7. Costs for the installation vessel depending on wave height.

The results of the measurement campaign have shown that it is technically possible to carry out successful installations in the range of up to $1.6 \mathrm{~m}$ safely and reliably with the use of the tuned mass damper; without a tuned mass damper, the limit for the installation of the rotor blades is $1.0 \mathrm{~m}$.

Looking at the charter rate alone and assuming $€ 120,000$ per day [6], the pure charter costs for an installation without dampers would be $€ 15,600,000$. With savings of $17.9 \%$, around $€ 2,800,000$ can be saved in charter costs alone, not including the costs for fuel and personnel. As mentioned at the beginning, the overall aim is to reduce the LcoE. The electricity production costs result from the capital costs, the fixed and variable operating costs, the fuel costs if applicable, and the targeted return on capital over the working period. In 2018, the LcoE for an offshore wind turbine was 7.49 to $13.79 € C$ Cent/ $\mathrm{kWh}$ [34]. A study by Fraunhofer ISE sees potential savings primarily in the costly installation of the systems [34]. These potentials were proven within the study carried out.

Figure 8 additionally shows the waiting times and the total operation time of the installation vessel in relation to the wave height. Again, it can be observed that the waiting time of the vessel can be significantly reduced with a significant wave height limit of $1.3 \mathrm{~m}$. The curve for the operation duration depends on the waiting time and therefore has a similar course.

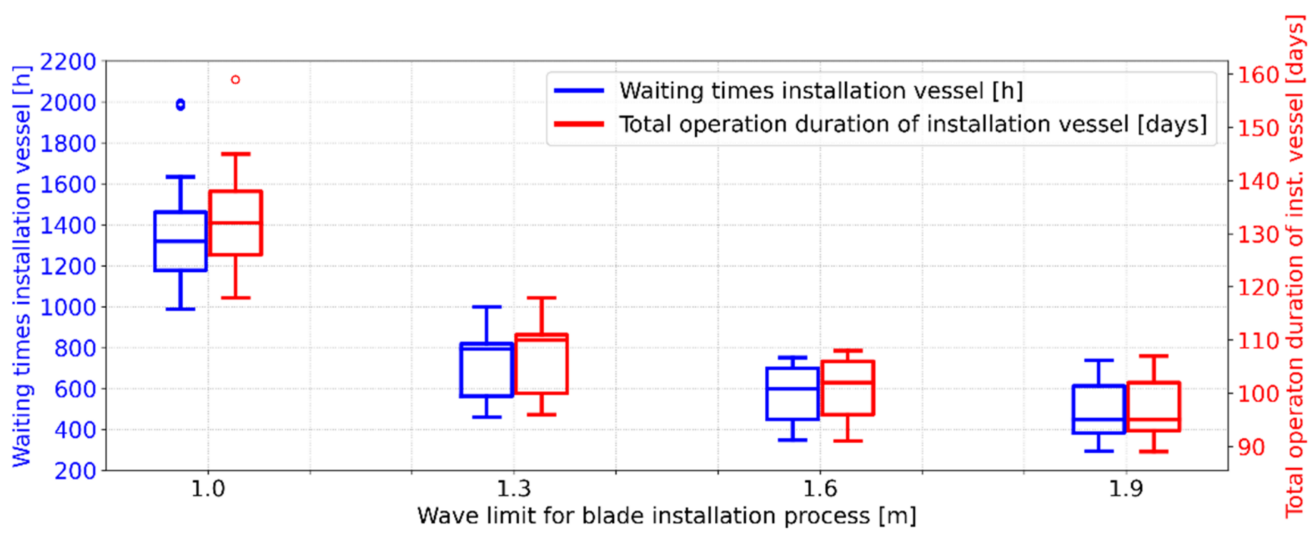

Figure 8. Distribution of waiting times and total operation duration depending on wave height.

Overall, it shows that the waiting times, and thus, the costs for the installation vessel can be significantly reduced by using a tuned mass damper. In order to be able to evaluate the use of the technology conclusively, the costs for the development and production of the technology would have to be compared to the potential savings. Unfortunately, this data is not available, whereby the costs for a damper are estimated at $€ 50,000$ per piece. However, it can be assumed that the amortization can easily be realized within the installation of a wind park, such as TWBII. 


\section{Conclusions and Outlook}

This study showed the influence of increasing wave height limits during the installation of rotor blades. The measurement campaign showed that wave height is the crucial parameter for installing the rotor blades. For this reason, only this parameter was varied in the discrete event simulation, and, for example, the limits for the wind speed were kept the same.

It was shown that even a slight increase in the wave limit from 1.0 to $1.3 \mathrm{~m}$ represents a savings potential of $13.1 \%$ (median) for the costs of the installation vessel. Increasing the wave limit requires the use of specialized technology, in this case, tuned mass dampers. The use of this technology leads to a reduction in LCoE, making offshore wind energy a more competitive energy source and represents a contribution to satisfying the ongoing demand for sustainable and renewable energy.

In future studies, a detailed cost analysis for the use of tuned mass dampers will be performed. The tuned mass dampers used in the measurement campaign were explicitly designed for the wind turbines installed in the TWBII wind park. It needs to be investigated how much cost and effort is required to modify such a mass damper for a different wind turbine type and investigate the overall development costs, product costs, and maintenance costs of such mass dampers, and how often they can be reused.

Furthermore, it also needs to be investigated if the determined savings from this study are transferable in general. For this, weather and other installation conditions of the North Sea need to be compared with those from other offshore installation locations, and the installation schedules and times need to be compared with those from other installation campaigns.

Other than that, we also plan to identify further bottlenecks in the installation process through a systematic approach. This can also be done, for example, using CFD simulations instead of costly measurement campaigns.

Author Contributions: All the authors contributed to this paper. Conceptualization, S.O., A.S. and M.F.; methodology, S.O. and A.S.; software, A.A.-A., M.K.; validation, S.O., A.S. and A.A.-A.; resources, S.O.; data curation, S.O., A.S. and A.A.-A.; writing-original draft preparation, S.O. and A.S.; writing-review and editing, M.K., A.A.-A. and M.F.; visualization, S.O. and A.S.; supervision, M.F. All authors have read and agreed to the published version of the manuscript.

Funding: This work is part of the project SKILLS—Development and demonstration of a rapid and cost-effective installation concept for offshore wind turbines, funded by the German Federal Ministry of Economy and Energy (funding code 0325934B), following a decision of the German Bundestag.

Institutional Review Board Statement: Not applicable.

Informed Consent Statement: Not applicable.

Data Availability Statement: Measurement data are available at: https:/ / doi.org/10.5281/zenodo. 4498779.

Conflicts of Interest: The authors declare no conflict of interest.

\section{References}

1. Kausche, M.; Adam, F.; Dahlhaus, F.; Großmann, J. Floating offshore wind-Economic and ecological challenges of a TLP solution. Renew. Energy 2018, 126, 270-280. [CrossRef]

2. Barlow, E.; Tezcaner Öztürk, D.; Revie, M.; Boulougouris, E.; Day, A.H.; Akartunalı, K. Exploring the impact of innovative developments to the installation process for an offshore wind farm. Ocean. Eng. 2015, 109, 623-634. [CrossRef]

3. Barlow, E.; Tezcaner Öztürk, D.; Revie, M.; Akartunalı, K.; Day, A.H.; Boulougouris, E. A mixed-method optimisation and simulation framework for supporting logistical decisions during offshore wind farm installations. Eur. J. Oper. Res. 2018, 264, 894-906. [CrossRef]

4. Beinke, T.; Ait Alla, A.; Freitag, M. Resource Sharing in the Logistics of the Offshore Wind Farm Installation Process based on a Simulation Study. Int. J. e-Navig. Marit. Econ. 2017, 7, 42-54. [CrossRef]

5. Byon, E.; Pérez, E.; Ding, Y.; Ntaimo, L. Simulation of wind farm operations and maintenance using discrete event system specification. SIMULATION 2011, 87, 1093-1117. [CrossRef] 
6. Oelker, S.; Ait Alla, A.; Lütjen, M.; Lewandowski, M.; Freitag, M.; Thoben, K.D. A simulation study of feeder-based installation concepts for offshore wind farms. In Proceedings of the Twentyeighth International Ocean and Polar Engineering Conference, Sapporo, Japan, 10-15 June 2018; Chung, J.S., Hyun, B.S., Matskevitch, D., Wang, A.M., Eds.; pp. 578-583.

7. Sander, A.; Haselsteiner, A.F.; Barat, K.; Janssen, M.; Oelker, S.; Ohlendorf, J.H.; Thoben, K.-D. Relative Motion during Single Blade Installation: Measurements from the North Sea. In Proceedings of the 39th International Conference on Ocean, Offshore and Arctic Engineering; ASME Digital Collection, Virtual, Online, 3-7 August 2020; Volume 9, pp. 1-10.

8. Sander, A.; Meinhardt, C.; Thoben, K.-D. Monitoring of offshore wind turbines under wave and wind loading during installation. In Proceedings of the EURODYN 2020 XI International Conference on Structural Dynamics, Athens, Greece, $22-24$ June 2020.

9. Sander, A. Oscillations of Offshore Wind Turbines undergoing Installation I: Raw Measurements (Version 2). 2020. Available online: https: / / zenodo.org/record/4498779\#.YNFg7kwRWM8 (accessed on 8 June 2021).

10. Bhattacharya, S. Challenges in Design of Foundations for Offshore Wind Turbines. Inst. Eng. Technol. 2014, 1. [CrossRef]

11. Musial, W.; Butterfield, S.; Ram, B. Energy from Offshore Wind. In Proceedings of the Offshore Technology Conference, Houston, TX, USA, 1-4 May 2006. [CrossRef]

12. Ait Alla, A.; Oelker, S.; Lewandowski, M.; Freitag, M.; Thoben, K.D. A Study of new Installation Concepts of Offshore Wind Farms by Means of Simulation Model. In Proceedings of the 27th International Ocean and Polar Engineering Conference, San Francisco, CA, USA, 25-30 June 2017.

13. Jiang, Z. Installation of offshore wind turbines: A technical review. Renew. Sustain. Energy Rev. 2021, 139. [CrossRef]

14. Jiang, Z. The impact of a passive tuned mass damper on offshore single-blade installation. J. Wind Eng. Ind. Aerodyn. 2018, 176, 65-77. [CrossRef]

15. Jiang, Z.; Skrudland, T.K.; Karimirad, M.; Machiladies, C.; Shi, W. Effect of a Passive Tuned Mass Damper on Offshore Installation of a Wind Turbine Nacelle. In Proceedings of the ASME 2020 39th International Conference on Ocean, Offshore and Arctic Engineering, American Society of Mechanical Engineers Digital Collection, Virtual, Online, 3-7 August 2020. [CrossRef]

16. Verma, A.S.; Jiang, Z.; Gao, Z.; Vedvik, N.P. Effects of a passive tuned mass damper on blade root impacts during the offshore mating process. Mar. Struct. 2020, 72, 102778. [CrossRef]

17. Ait Alla, A.; Quandt, M.; Lütjen, M. Simulation-based aggregate installation planning of offshore wind farms. Int. J. Energy 2013, $72,23-30$.

18. Irawan, C.A.; Jones, D.; Ouelhadj, D. Bi-objective optimisation model for installation scheduling in offshore wind farms. Comput. Oper. Res. 2017, 78, 393-407. [CrossRef]

19. Rippel, D.; Jathe, N.; Lütjen, M.; Freitag, M. A Mixed-Integer Formulation to Optimize the Resupply of Components for the Installation of Offshore Wind Farms. In Proceedings of the 2020 Winter Simulation Conference, Orlando, FL, USA, 14-18 December 2020; Bae, K.-H., Feng, B., Kim, S., Lazarova-Molnar, S., Zheng, Z., Roeder, T., Thiesing, R., Eds.; IEEE: New York, NY, USA, 2020; pp. 1420-1431.

20. Tekle Muhabie, Y.; Rigo, P.; Cepeda, M.; de Almeida D'Agosto, M.; Caprace, J.D. A discrete event simulation approach to evaluate the effect of stochastic parameters on offshore wind farms assembly strategies. Ocean. Eng. 2018, 149, 279-290. [CrossRef]

21. Vis, I.F.; Ursavas, E. Assessment approaches to logistics for offshore wind energy installation. Sustain. Energy Technol. Assess. 2016, 14, 80-91. [CrossRef]

22. Rippel, D.; Jathe, N.; Becker, M.; Lütjen, M.; Szczerbicka, H.; Freitag, M. A Review on the Planning Problem for the Installation of Offshore Wind Farms. IFAC PapersOnLine 2019, 52, 1337-1342. [CrossRef]

23. Maes, K.; De Roeck, G.; Lombaert, G. Motion tracking of a wind turbine blade during lifting using RTK-GPS/INS. Eng. Struct. 2018, 172, 285-292. [CrossRef]

24. Qiu, Y.; Feng, Y.; Tavner, P.; Richardson, P. Wind turbine SCADA alarm analysis for improving reliability. Wind Energy 2012, 15, 951-966. [CrossRef]

25. Feng, Y.; Qiu, Y.; Crabtree, C.; Long, H.; Tavner, P. Use of SCADA and CMS signals for failure detection and diagnosis of a wind turbine gearbox. EWEA 2011. [CrossRef]

26. Kim, K.; Parthasarathy, G.; Uluyol, O.; Foslien, W. Use of SCADA data for failure detection in wind turbines. In Proceedings of the Energy Sustainability Conference and Fuel Cell Conference, Washington, DC, USA, 7-10 August 2011.

27. Wang, Y.; Infield, D. Supervisory control and data acquisition data-based non-linear state estimation technique for wind turbine gearbox condition monitoring. IET Renew. Power Gener. 2012, 7, 350-358. [CrossRef]

28. Verma, A.S.; Jiang, Z.; Ren, Z.; Gao, Z.; Vedvik, N.P. Response-Based Assessment of Operational Limits for Mating Blades on Monopile-Type Offshore Wind Turbines. Energies 2019, 12, 1867. [CrossRef]

29. Shankar Verma, A.; Jiang, Z.; Ren, Z.; Caboni, M.; Verhoef, H.; van der Mijle-Meijer, H.; Castro, S.G.; Teuwen, J.J. A probabilistic long-term framework for site-specific erosion analysis of wind turbine blades: A case study of 31 Dutch sites. Wind Energy 2021, 1-22. [CrossRef]

30. Jiang, Z.; Gao, Z.; Ren, Z.; Li, Y.; Duan, L. A parametric study on the final blade installation process for monopile wind turbines under rough environmental conditions. Eng. Struct. 2018, 172, 1042-1056. [CrossRef]

31. Ren, Z.; Jiang, Z.; Gao, Z.; Skjetne, R. Active tugger line force control for single blade installation. Wind Energy 2018, 21, 1344-1358. [CrossRef]

32. Freiheit, T. Installationskosten von Offshore-Windenergieparks: Einfluss eines Schwingungstilgers auf die Rotorblattinstallation (Bachelor of Science); University of Bremen: Bremen, Germany, 2021. 
33. Helmholtz-Zentrum Geesthacht, Zentrum für Material- und Küstenforschung GmbH. coastDat-1 Waves North Sea wave spectra hindcast (1948-2007). World Data Center for Climate (WDCC) am DKRZ. Available online: https:/ /doi.org/10.1594/WDCC/ coastDat-1_Waves (accessed on 7 June 2021).

34. Fraunhofer Institut for Solar Energy Systems. Stromgestehungskosten erneuerbarer Energien-Studie. $2018 . \quad$ Available online: https://www.ise.fraunhofer.de/content/dam/ise/de/documents/publications/studies/DE2018_ISE_Studie_ Stromgestehungskosten_Erneuerbare_Energien.pdf (accessed on 7 June 2021). 